\title{
Whole-Genome Expression Profiling Defines the HrpL Regulon of Pseudomonas syringae pv. tomato DC3000, Allows de novo Reconstruction of the Hrp cis Element, and Identifies Novel Coregulated Genes
}

\author{
Adriana O. Ferreira, ${ }^{1}$ Christopher R. Myers, ${ }^{2}$ Jeffrey S. Gordon, ${ }^{1}$ Gregory B. Martin, ${ }^{1,3}$ Monica Vencato, ${ }^{3}$ \\ Alan Collmer, ${ }^{3}$ Misty D. Wehling, ${ }^{4}$ James R. Alfano, ${ }^{4}$ Gabriel Moreno-Hagelsieb, ${ }^{5}$ Warren F. Lamboy, ${ }^{5}$ \\ Genevieve DeClerck, ${ }^{5}$ David J. Schneider, ${ }^{5}$ and Samuel W. Cartinhour ${ }^{5}$ \\ ${ }^{1}$ Boyce Thompson Institute for Plant Research, Ithaca, NY 14853, U.S.A.; ${ }^{2}$ Cornell Theory Center, Cornell University, Ithaca, \\ NY 14853, U.S.A.; ${ }^{3}$ Department of Plant Pathology, Cornell University, Ithaca, NY 14853, U.S.A.; ${ }^{4}$ The Plant Science \\ Initiative and the Department of Plant Pathology, University of Nebraska-Lincoln, Lincoln, 68588, U.S.A.; ${ }^{5}$ United States \\ Department of Agriculture-Agricultural Research Service, Ithaca, NY 14853, U.S.A.
}

Submitted 28 January 2006. Accepted 2 July 2006.

\begin{abstract}
Pseudomonas syringae pv. tomato DC3000 is a model pathogen of tomato and Arabidopsis that uses a hypersensitive response and pathogenicity (Hrp) type III secretion system (T3SS) to deliver virulence effector proteins into host cells. Expression of the Hrp system and many effector genes is activated by the HrpL alternative sigma factor. Here, an open reading frame-specific whole-genome microarray was constructed for DC3000 and used to comprehensively identify genes that are differentially expressed in wild-type and $\Delta h r p L$ strains. Among the genes whose differential regulation was statistically significant, 119 were upregulated and 76 were downregulated in the wild-type compared with the $\Delta h r p L$ strain. Hierarchical clustering revealed a subset of eight genes that were upregulated particularly rapidly. Gibbs sampling of regions upstream of HrpL-activated operons revealed the Hrp promoter as the only identifiable regulatory motif and supported an iterative refinement involving real-time polymerase chain reaction testing of additional HrpL-activated genes and refinements in a hidden Markov model that can be used to predict Hrp promoters in $\boldsymbol{P}$. syringae strains. This iterative bioinformatic-experimental approach to a comprehensive analysis of the HrpL regulon revealed a mix of genes controlled by $\mathrm{HrpL}$, including those encoding most type III effectors, twin-arginine transport (TAT) substrates, other regulatory proteins, and proteins involved in the synthesis or metabolism of phyto-
\end{abstract}

\section{A. O. Ferreira and C. R. Myers contributed equally to this work.}

Corresponding author: Samuel W. Cartinhour; E-mail: sc167@ cornell.edu

Current address of G. Moreno-Hagelsieb: Department of Biology, Wilfrid Laurier University, Waterloo, Ontario N2L 3C5, Canada.

* The $\boldsymbol{e}$-Xtra logo stands for "electronic extra" and indicates the HTML abstract available on-line contains supplemental material not included in the print edition. There are four supplemental tables and one supplemental figure.

This article is in the public domain and not copyrightable. It may be freely reprinted with customary crediting of the source. The American Phytopathological Society, 2006. hormones, phytotoxins, and myo-inositol. This analysis provides an extensively verified, robust method for predicting Hrp promoters in $P$. syringae genomes, and it supports subsequent identification of effectors and other factors that likely are important to the host-specific virulence of $P$. $s y$ ringae.

Additional keywords: weight matrix model.

Pseudomonas syringae pv. tomato DC3000 is a pathogen of tomato and Arabidopsis that translocates virulence effector proteins into host cells via a type III secretion system (T3SS). Regulation of the T3SS is known to depend on the ECF-type sigma factor HrpL (Xiao et al. 1994). The identification of hypersensitive response and pathogenicity (Hrp) promoters and genes expressed in a HrpL-dependent manner is key to understanding $P$. syringae as a plant pathogen for several reasons. First, most T3SS effectors are associated with Hrp promoters, and identifying Hrp promoters is an efficient first step in identifying candidate effector genes (Chang et al. 2005; Fouts et al. 2002; Zwiesler-Vollick et al. 2002). Second, genes with no apparent function in the T3SS that nevertheless are activated (directly or indirectly) by $\mathrm{HrpL}$ are likely to have a significant role in pathogenesis. A notable example is found in the genes directing synthesis of the phytotoxin coronatine (Chang et al. 2005; Fouts et al. 2002; Peñaloza-Vázquez et al. 2000). Third, $P$. syringae strains are divided into more than 50 pathovars and multiple races based on host specificity and have remarkably diverse interactions with plants (Hirano and Upper 2000). Polymorphisms in the HrpL regulon (particularly among the effectors) are known to underlie some of this diversity (Arnold et al. 2003; Rohmer et al. 2004), and methods to efficiently identify Hrp promoters in genome sequences should improve our understanding of this phenomenon as well as provide useful diagnostic tools. Our purpose here is to use a microarray-based iterative approach to comprehensively identify all of the Hrp promoters in the model pathogen $P$. syringae pv. tomato DC3000 and to develop improved methods for identifying Hrp promoters in the sequences of any new $P$. syringae strains. 
In previous work, we initiated our analysis of the HrpL regulon in P. syringae pv. tomato DC3000 by using a reporter transposon to enlarge the set of known, functional Hrp promoters, which enabled the training of a hidden Markov model (HMM) that was used to search a draft sequence of the DC3000 genome (Fouts et al. 2002). Six of the candidate promoters we found with strong expectation values were tested experimentally and confirmed to be activated by HrpL. Downstream of these promoters were several known effectors and candidate effectors, as well as genes encoding factors unrelated to the T3SS, such as iaaL and corR. The process of experimentally identifying HrpLresponsive genes in DC3000 was carried to near saturation using differential fluorescence induction (Chang et al. 2005), which resulted in the identification of $49 \mathrm{HrpL}$-responsive genes and corroborated our previous findings (Fouts et al. 2002). A limitation of these two studies is that both involved overexpression of HrpL, and neither provided time-course data on the expression of the HrpL regulon. Thus, it is important to note that the microarray analysis presented in this study follows changes in gene expression of wild-type and $\Delta h r p L$ strains for several hours following transfer to Hrp-inducing conditions.

Here, we report i) the use of an open reading frame (ORF)specific whole genome microarray for $P$. syringae pv. tomato DC3000 to comprehensively identify genes that are differentially expressed in wild-type and HrpL-deficient strains; ii) Gibbs sampling for de novo identification of Hrp promoter sequences upstream of HrpL-activated genes that were identified in the microarray; iii) development of a hidden Markov model and position-specific weight matrix (PSWM) model based on a microarray-derived training set, which was used to comprehensively identify candidate Hrp promoters in the complete genome of DC3000; iv) real-time polymerase chain reaction (PCR) confirmation of candidate Hrp promoters that were missed by the microarray analysis; and v) analysis of Hrp promoters and downstream genes in the context of predicted operons, genome annotation errors, and functions of the HrpL regulon in pathogenesis.

\section{RESULTS}

\section{Clustering of microarray expression data.}

Our analysis of microarray expression levels, described in Materials and Methods, yielded a set of 119 genes that satisfied the criteria for significant differential upregulated expression (DEG-UP), and 76 genes with significant downregulated expression (DEG-DOWN) in the wild-type compared with the $\Delta h r p L$ strain. (One gene, PSPTO0067, exhibited both significant upregulation and downregulation at different time points.) The full set we refer to collectively as DEG-ALL, whose differential expression levels, along with their gene identifiers, are presented in Figure 1A. Hierarchical clustering of the expression data reveals a subcluster with highly correlated expression (Fig. 1A-1) which, upon further inspection, is seen to contain known T3SS components, including $h r p / h r c$ genes and effectors. The general character of these clustering results is insensitive to specific details of the algorithm, particularly if correlation-based distance metrics are used to relate expression patterns. Clustering of the upregulated gene set DEG-UP (data not shown), using fold changes rather than their logs, yields a similar tightly correlated subcluster, including the known T3SS components. Subclusters 3 and 4 constitute the bulk of the downregulated gene set DEGDOWN, a set that, to our knowledge, has not been described previously. Subcluster 2 consists largely of a set of genes that are upregulated at time $t=0 \mathrm{~h}$.

Gibbs sampling upstream of differentially expressed genes.

From the set of differentially expressed genes, Gibbs sampling was carried out to search for conserved regulatory motifs.
Gibbs sampling of the set of candidate regulatory regions, targeted toward finding promoter-sized objects (e.g., size 30 to 40 bases), consistently identified and clustered a motif consistent with the consensus sequence previously associated with the Hrp promoter, 5'-GGAAC-N $16-17-C C A C N N A-3$ ' (Fouts et al. 2002; Innes et al. 1993; Shen and Keen 1993; Xiao and Hutcheson 1994). This observation is true for sampling done on both the upstream regions of the full DEG-ALL set and the upregulated DEG-UP set. For sampling done on the DEG-UP set, with motif size 33, the average cluster occupancies of all sequences clustered in the Hrp promoter motif are plotted in Figure 2. Sequences with separations of length 16 and 17 between the -35 and -10 boxes are clustered together by the Gibbs sampler. A few stray sequences occasionally are included in the Hrp promoter cluster during the sampling process, but Figure 2 demonstrates that there is a clear separation between a set of sequences that is strongly clustered and a few outliers that are not. For further analysis, we have kept only those sequences whose average occupancy was greater than $50 \%$. Because of the differing separation lengths within the population of putative Hrp promoters, it was useful for some purposes to align the set of sequences clustered by the Gibbs sampler for further analysis. Alignment of the motifs with separation of length 17 to the set of length 16 using ClustalX (Thompson et al. 1997) yielded a combined model with gaps (for construction of HMMs).

Although Gibbs sampling located the Hrp promoter motif, sampling of the upstream sequence regions associated with the DEG-ALL, DEG-UP, and DEG-DOWN sets and various subsets did not consistently identify any other strongly conserved sequence motifs. Furthermore, models of other regulatory motifs that we have constructed (e.g., Fur, RpoN, RpoS, and RpoD promoters) do not reveal putative binding sites in the DC3000 genome that are correlated with the sets of differentially expressed genes identified by the microarray.

\section{Construction of initial Gibbs-derived motif models.}

The set of motifs clustered by the Gibbs sampler (with occupancy greater than 50\%) was used to construct HMM and PSWM models of the Hrp promoter motif. (These are denoted as our "level 1" training set.) The entire DC3000 genome then was scanned using these models to identify putative Hrp promoters whose targets might not have been identified by the microarray. Several such genes were identified, with upstream promoters scoring greater than 10 by the HMM. Some of those genes were not represented on our microarray due to technical problems, some did not meet our criteria for statistically significant differential expression but are in polycistronic operons with genes that were differentially expressed, and some simply did not meet our cutoff criteria.

\section{Real-time PCR confirmation of additional Hrp promoters.}

Our hypothesis was that genes with strong upstream Hrp promoters should exhibit significant upregulation in the microarray. That was largely true; however, for a handful of genes that did not fit that scenario, real time-PCR was used as a more sensitive but less high-throughput method of determining HrpL-dependent expression. Ten genes with strong Hrp promoters (HMM level 1 score $>10$ ) but no significant differential expression in the microarray were analyzed by real time-PCR. Of those 10 , PSPTO0474 and PSPTO4776 had exhibited differential expression under HrpL overexpression (Fouts et al. 2002), and PSPTO1394 was not on our microarray. One unannotated region downstream of a strong putative promoter, upstream of PSPTO0869, also was tested for real time-PCR. Two genes (PSPTO4732 and PSPTOB0005) that were in the DEG-UP set but are rather far downstream from a putative Hrp promoter also were tested, as was one gene (PSPTO2691) that was also in 
DEG-UP but does not have any identifiable upstream promoter. Two putative transcriptional regulators (PSPTO3576 and PSPTO1645) that were not in DEG-UP also were tested; PSPTO3576 has a rather weak promoter (HMM level 1 score $=$ 7.1), whereas PSPTO1645 has a stronger promoter (HMM level $1=12.4$ ) which is embedded in an upstream gene roughly 700 bp from the transcription start of PSPTO1645. Finally, two housekeeping genes were included as negative controls. For these 18 cases, real time-PCR assays were done using both the condition investigated here ( $h r p L$ deletion mutant in HrpMM) and that investigated in earlier work ( $h r p L$ overexpression in $\mathrm{AB}$ media).
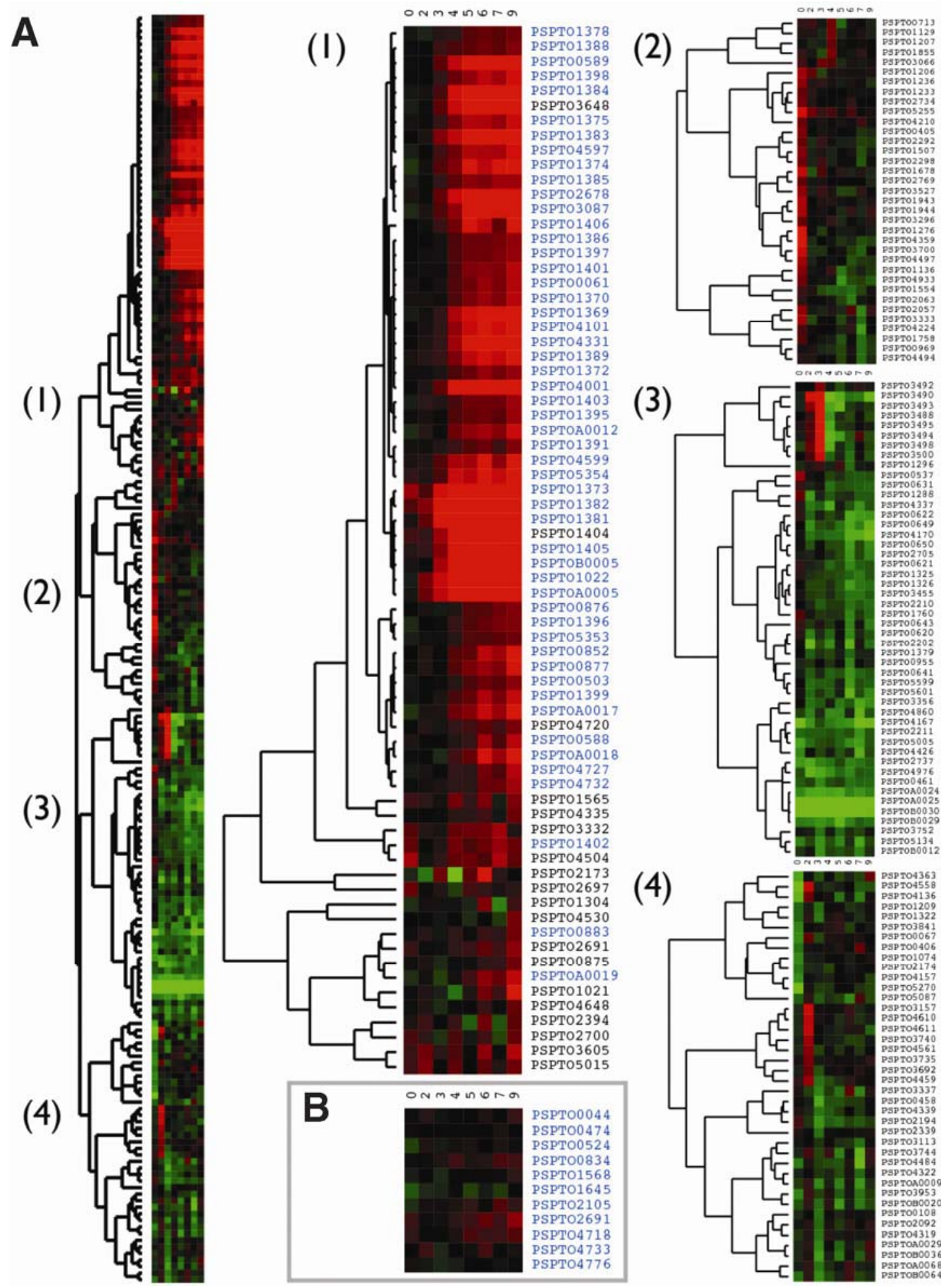

(3)

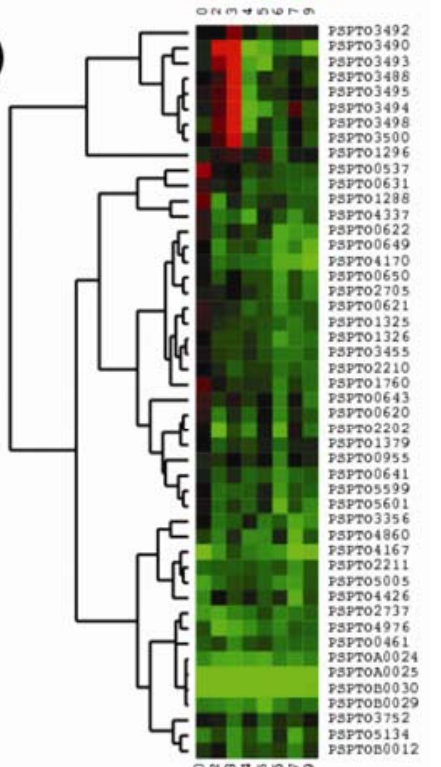

(4)

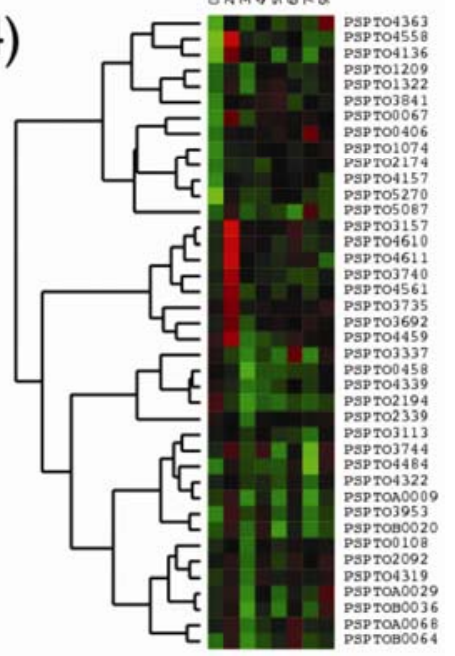

Fig. 1. Differentially expressed genes as detected by A, microarray or $\mathbf{B}$, real-time polymerase chain reaction (RT-PCR). The microarray expression levels are hierarchically clustered, and broken out into four clusters ( 1 to 4$)$ as shown. Gene names presented in blue font are those that either were found by the Gibbs sampler to contain an upstream hypersensitive response and pathogenicity (Hrp) promoter or subsequently inferred to be part of an operon with an upstream Hrp promoter (PSPTOA0018, PSPTOA0019, and PSPTOB0005). Subcluster 1 is the most tightly clustered (as indicated by the short depth of the clustering tree to the left), and all Hrp promoters associated with upregulated genes in the microarray are found in that subcluster. 
The results of the real time-PCR experiments are shown in Table 1. HrpL-dependent expression was confirmed or reconfirmed for 14 genes or ORFs with strong Hrp promoters (PSPTO0044, PSPTO0474, PSPTO0524, PSPTO0834, PSPTO1394, PSPTO1568, PSPTO1645, PSPTO2105,

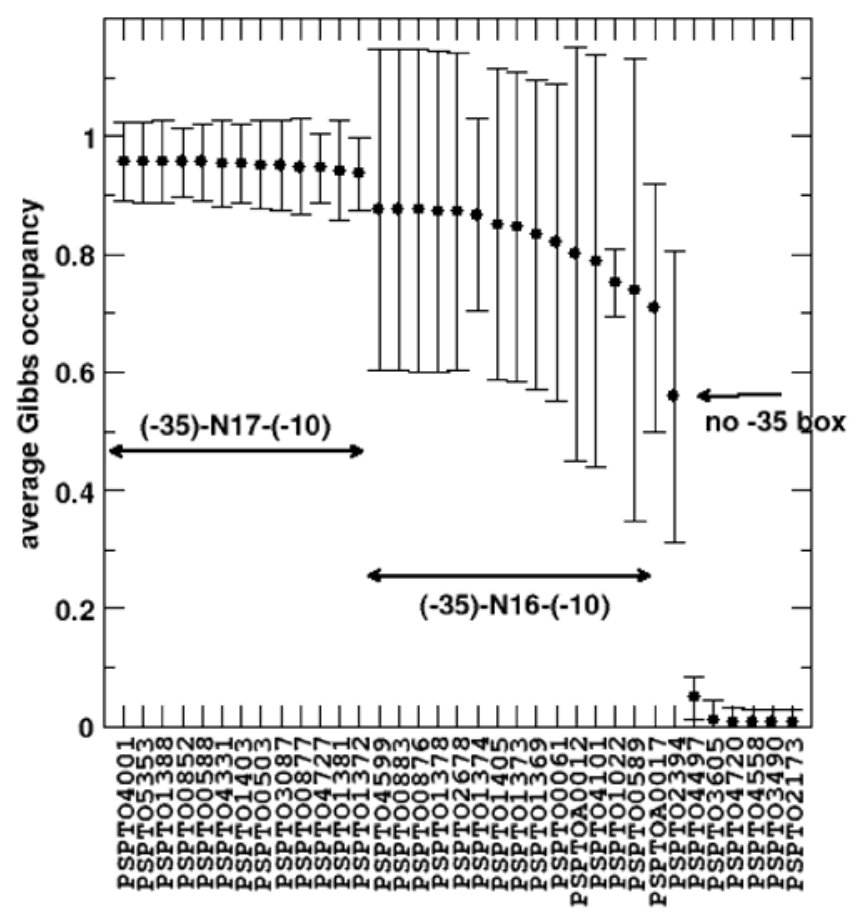

Fig. 2. Average occupancy of upstream sequence motifs within the dominant hypersensitive response and pathogenicity (Hrp)-promoter-related Gibbs cluster (averaged over 10 runs). The set of 13 genes highly clustered with occupancy near 1.0 represent most of the Hrp promoters with spacer length 17. The next set of 15 genes with slightly lower occupancies are primarily those with spacer length 16. Error bars represent standard deviations from the set of 10 occupancy scores (even though no occupancy scores can exceed 1.0 in a given run); if a given gene fails to be included in the cluster in a given run, it is assigned an occupancy score of 0 for that run.
PSPTO4718, PSPTO4732, PSPTO4733, PSPTO4776, PSPTOB0005, and the unannotated region upstream of PSPTO0869). PSPTO2691 was reconfirmed to be HrpL dependent despite the lack of a Hrp promoter. Only one of the two putative regulators (PSPTO1645) with weak or dubious Hrp promoters exhibited differential expression based upon real time-PCR. The two housekeeping genes used as negative controls were shown to not be regulated by HrpL in this experiment. Generally, little significant difference in the log of the expression fold change was observed between the two conditions (HrpL deletion versus HrpL overexpression) for the genes tested here.

\section{Correlation \\ of Hrp promoter motifs and microarray clustering.}

With the identification of Hrp promoters from the combination of bioinformatics and further bioinformatically directed experimentation, we can revisit the clustering of microarray expression data in Figure 1 to examine correlations between clustering and sequence motifs. The genes annotated in Fig. 1A with blue font are those with upstream Hrp promoters. All upstream Hrp promoters are associated with the tightly correlated subcluster in Fig. 1A-1 and, in fact, most of that subcluster involves direct regulation via an Hrp promoter. Furthermore, those genes without Hrp promoters lie in the less tightly clustered subset at the bottom of subcluster 1. Also shown in blue font in Fig. 1B are those genes with Hrp promoters that were identified to be HrpL dependent via real time-PCR. (Their microarray expression levels also are shown, but not clustered; the fact that those expression levels are mostly black reflects the fact that those genes did not exhibit significant differential expression in the microarray.)

\section{Construction of refined motif models from Gibbs sampling and real time-PCR.}

The Gibbs-derived motif training set (level 1, described above) was augmented and realigned with Hrp promoter sequences upstream of genes confirmed to be $\mathrm{HrpL}$ dependent via real time-PCR, resulting in a refined training set ("level 2") and associated HMM and PSWM motif models which were

Table 1. Results of real-time polymerase chain reaction analysis

\begin{tabular}{|c|c|c|c|c|c|}
\hline PSPTO no. ${ }^{a}$ & $\begin{array}{c}\Delta \text { LogC: } \\
\text { WT vs. } \Delta h r p L^{b}\end{array}$ & $\begin{array}{l}\text { Fold change: } \\
\text { WT vs. } \Delta h r p L\end{array}$ & $\begin{array}{c}\Delta \mathrm{LogC}: \Delta h r p / h r c+h r p L \\
\text { vs. } \Delta h r p / h r c\end{array}$ & $\begin{array}{c}\text { Fold change: } \\
\Delta h r p / h r c+h r p L \text { vs. } \Delta h r p / h r c\end{array}$ & Protein \\
\hline 0044 & $0.85 \pm 0.55$ & 7.10 & $0.38 \pm 0.22$ & 2.41 & HopK1 \\
\hline 0474 & $0.45 \pm 0.27$ & 2.80 & $0.65 \pm 0.64$ & 4.51 & Hypothetical protein \\
\hline 0524 & $0.83 \pm 0.42$ & 6.71 & $0.86 \pm .045$ & 7.22 & Peptidase, M20/M25/M40 \\
\hline 0834 & $1.89 \pm 0.53$ & 76.80 & $1.82 \pm 0.33$ & 65.76 & Alcohol dehydrogenase \\
\hline $5617 *$ & $0.52 \pm 0.37$ & 3.34 & $0.22 \pm 0.27$ & 1.64 & Unannotated \\
\hline 1394 & $1.95 \pm 0.51$ & 88.70 & N/A & N/A & $\mathrm{HrcS}$ \\
\hline 1568 & $1.71 \pm 0.47$ & 51.10 & $1.13 \pm 0.32$ & 13.38 & HopAF1 \\
\hline 1645 & $0.65 \pm 0.56$ & 4.50 & $0.19 \pm 0.15$ & 1.54 & Transcr. regulator, MarR family \\
\hline 2105 & $1.51 \pm 0.41$ & 32.02 & $1.10 \pm 0.39$ & 12.61 & ApbE-family protein \\
\hline 2691 & $0.80 \pm 0.34$ & 6.28 & $0.13 \pm 0.15$ & 1.35 & Membrane prot., TerC family \\
\hline 3576 & $-0.05 \pm 0.27$ & 0.90 & $-0.03 \pm 0.15$ & 0.93 & TvrR (Preiter et al. 2005) \\
\hline 3648 & $1.41 \pm 0.49$ & 25.59 & $0.57 \pm 0.37$ & 3.70 & Acid phosphatase \\
\hline 4718 & $1.82 \pm 0.43$ & 66.46 & $1.07 \pm 0.28$ & 11.80 & HopAA1-2 \\
\hline 4732 & $1.64 \pm 0.48$ & 43.23 & $0.71 \pm 0.30$ & 5.10 & HopQ1-2 \\
\hline 4733 & $1.01 \pm 0.39$ & 10.22 & $0.26 \pm 0.14$ & 1.83 & Hypothetical protein \\
\hline 4776 & $2.51 \pm 0.65$ & 323.10 & $1.52 \pm 0.62$ & 33.49 & HopI1 \\
\hline B0005 & $1.39 \pm 0.45$ & 24.73 & $0.59 \pm 0.30$ & 3.92 & Phosphoesterase \\
\hline 1287 & $0.07 \pm 0.29$ & 1.18 & $-0.08 \pm 0.12$ & 0.82 & Gap-1 (housekeeping) \\
\hline 1745 & $-0.03 \pm 0.23$ & 0.93 & $0.10 \pm 0.15$ & 1.26 & GyrA (housekeeping) \\
\hline
\end{tabular}

${ }^{a}$ PSPTO number indicates gene tested. An asterisk indicates a new gene call based on this work.

${ }^{\mathrm{b}} \triangle \mathrm{LogC}$ is the difference of the logarithm (base 10) of relative mRNA concentrations between the two identified strains or conditions of DC3000. The values reported represent the mean \pm the standard deviation of three biological replicates for each sample; normalization to levels for gap-1 and gyrA as described in Materials and Methods. Fold change represents $10^{\Delta \log \mathrm{C}}$. Differential expression for $\Delta h r p / h r c+h r p L$ versus $\Delta h r p / h r c$ was not available (N/A) for PSPTO1394 because it is deleted in that set of strains. Abbreviations in the protein designations: transcr. $=$ transcriptional, biosynth. $=$ biosynthesis, prot. $=$ protein. 
used to rescan the DC3000 genome for putative Hrp promoters. The refinement of the motif model associated with the incremental sequences added in level 2 did not produce HMM and PSWM scores that differed dramatically from their level 1 values. Nor did either the level 1 or level 2 scores differ substantially from those associated with our level 0 training set; namely, that reported by Fouts and associates (2002) with corrections as described below. Receiver-operator characteristic (ROC) scores indicate (data not shown) that all three sets of models (levels 0,1 , and 2 ) have roughly equal discriminating power (area under the ROC curve). All are highly discriminating, and our new level 2 models do not represent a significant refinement over the previous level 0 models. A sequence logo (Crooks et al. 2004) for this refined motif is shown in Figure 3, juxtaposed with that derived from the level 0 sequence training set.

The results of our genomewide scans for Hrp promoter motifs are summarized in Figure 4, which plot maximal expression fold change versus HMM level 2 score, for each operon for which an HMM score above a threshold of 6 is registered in the upstream promoter region (Fig. 4A); and distance from the start of a putative Hrp promoter to the annotated transcription start of the downstream target operon (Fig. 4B). Distances less than zero (i.e., below the dashed line) represent Hrp promoters upstream of the start site; negative distances near 0 (e.g., within 500 bases of the start site) most plausibly represent functional promoters. (As noted below, however, in some cases, where strong Hrp promoters occur far upstream of the nominal transcription start, we suspect that small unannotated genes lie more closely downstream of the promoter.) The lack of strong expression shown in Figure 4A for HMM scores $<10$ and the prevalence of presumably nonfunctional promoter start sites in Figure 4B for HMM score $<10$ suggest that this represents a reasonable cutoff for functional Hrp promoters. The HMM was constructed from training data for genes exhibiting significant differential expression; therefore, the fact that highly scoring Hrp promoters in Figure 4A correspond to upregulated genes is not surprising. Because the HMM sequence model reflects sequence similarity rather than actual binding affinity, however, we should not necessarily expect a strong correlation between score and expression level within the upregulated set (nor did we observe one).

Several Hrp promoter hits plotted in Figure 4A have high scores but are upstream of genes whose expression changes fell below our cutoff. A significant fraction of those composed the set retested via real time-PCR, as described above. Five additional genes showed differential expression with a fold change greater than 1.25 , but missed one or more of the
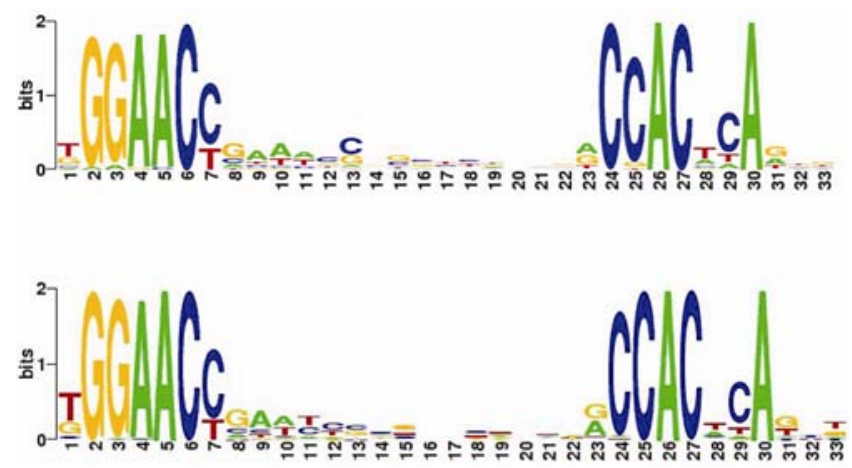

Fig. 3. Sequence logos of hypersensitive response and pathogenicity promoter motifs derived from Gibbs sampling of candidate regulatory regions identified by differential expression in microarray experiment (top) and by Fouts and associates (2002) based on literature searching and mini-Tn5gus mutagenesis (bottom). threshold criteria (PSPTO0371, PSPTO1377, PSPTO4589, PSPTO4718, and PSPTO4722). Three genes (PSPTO1392, PSPTO1393, and PSPTO1400) are members of the large HrpJ operon. All the remaining members of that operon exhibited significant differential expression and are included in the DEG-ALL set, and we infer that the missing three also should exhibit differential expression. In addition, several genes that were not on the microarray (PSPTO1387, PSPTO1390, PSPTO1394, PSPTO1408, PSPTO2679, and PSPTO4588) are not shown in Figure 4A. HrpL-dependent expression of PSPTO1394 was confirmed via real time-PCR. Based on their strong promoters, however, we would expect the rest of that missing set to show significant differential expression.

Our weight matrix (WM) models form a complementary perspective on candidate Hrp promoters. Generally, the HMM and WM scores are well correlated with each other, although
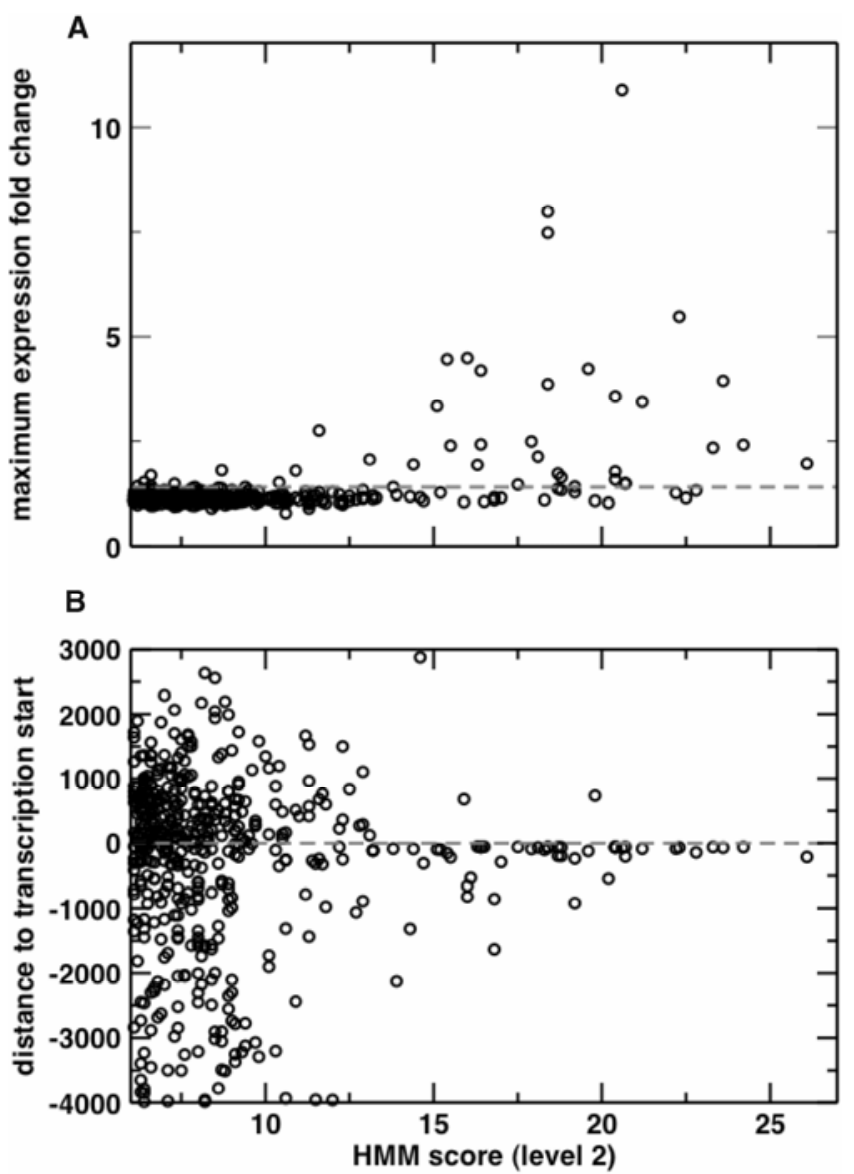

Fig. 4. Relationship between hidden Markov model (HMM) level 2 score and maximum HrpL-dependent expression change and distance of promoter from transcription start. A, Maximal expression fold change of target operon versus hypersensitive response and pathogenicity (Hrp) promoter HMM level 2 score (circles), along with the expression fold change cutoff used in our microarray analysis (dashed line). Some target operons have multiple putative Hrp promoter hits; in these cases, we keep only the Hrp promoter with the highest score. B, Distance from start of Hrp promoter to annotated start of transcription versus Hrp promoter HMM score. Distances less than zero (i.e., below the dashed line) represent Hrp promoters upstream of the start site; negative distances near 0 (e.g., within 500 bases of the start site) most plausibly represent functional promoters. The lack of strong expression in A for HMM score $<10$ and the prevalence of presumably nonfunctional promoter start sites in (b) for HMM score $<10$ suggest that this represents a reasonable cutoff for functional Hrp promoters. Hrp promoters in A that have a high score but exhibited differential expression below the threshold indicated either were among those subsequently tested for differential expression via quantitative real-time polymerase chain reaction, were not on the microarray, or belonged within putative operons with other genes that did exhibit differential expression. 
candidate promoter regions identified by the two models can differ at the margins (i.e., near an HMM cutoff score of 10.0 and a WM cutoff score of 4.0). We do not combine these separate scores into an aggregate score; rather, each model serves as a check on the other. We have found some candidate promoters for which there is experimental evidence of $\mathrm{HrpL}$ dependence, but whose HMM scores fall below our cutoff of 10 (both in DC3000, as reported here, and in P. syringae pv. phaseolicola 1448A, as reported by Vencato and associates [2006]). In all these cases, we find evidence of moderately strong coexisting WM scores of each variant (i.e., 16- and 17-bp spacers). It is possible that cooperative binding among the two promoter variants helps to stabilize binding of the RNA polymerase holoenzyme to the DNA, resulting in higher affinity binding than might be suggested by the bioinformatic models themselves.

\section{Corrections to genome annotation}

from bioinformatics and experimental evidence.

Our experimental results and analysis of Hrp promoters suggest several revisions to the original genome annotation presented by Buell and associates (2003), which we have compiled in an updated submission to GenBank to accompany this article. In several cases, we have observed strong Hrp promoters somewhat far upstream of genes (e.g., more than $200 \mathrm{bp}$ ) for which there is experimental evidence of HrpL-dependent expression. One such region, upstream of PSPTO0869, was tested and verified for HrpL-dependent transcription via real time-PCR (Table 1). Subsequent analysis reveals this region, which we have annotated with the new identifier PSPTO5617, to be a pseudogene with similarity to annotated genes in other pseudomonads. Another new gene call, upstream of PSPTOB0005 and now designated as PSPTOB0078, corresponds to a region downstream of a putative promoter in an unannotated region. A translated peptide fragment matching this region was detected by mass spectroscopy (data not shown). Furthermore, comparative analysis of long (nominally) untranslated regions (UTRs) downstream of candidate Hrp promoters, as well as unannotated regions in the vicinity of candidate promoters, reveals strong sequence similarity with orthologous regions in other sequenced pseudomonads. Given this evidence, we have decided to make calls for nine new genes, designated as PSPTO5616 to PSPTO5622, PSPTOA0072, and PSPTOB0078. A fragmentary pseudogene in the operon containing PSPTOA0017-A0019 (Guo et al. 2005 ) is consistent with our bioinformatic analysis indicating the existence of a single Hrp promoter upstream of the entire set of genes. Finally, our updated genome annotation file explicitly contains Hrp promoter features that were identified bioinformatically and which have experimental evidence of HrpLdependent transcription downstream. It should be noted that the corrected annotations typically occur in regions that have an anomalously low GC content relative to the rest of the genome or involve pseudogenes that are interrupted by premature stop codons or transposon insertions. These pseudogenes were detected by DNA- and protein-based sequence comparisons with apparently intact genes in other Pseudomonas spp.

\section{Summary of genes regulated \\ by Hrp promoters and methods used to identify them.}

Genes preceded by Hrp promoters for which we have reported either direct experimental evidence for HrpL-dependent transcription via microarray or real time-PCR (corresponding to the genes highlighted in blue in Figure 1), or for which we have inferred such transcription based on inclusion within a putative operon demonstrating HrpL-dependent transcription, are listed in Table 2. A summary flow plan for the iterative bio- informatic and experimental methods that were used to identify Hrp promoters in DC3000 is shown in Figure 5.

\section{DISCUSSION}

We have used a combination of approaches involving microarray analysis, Gibbs sampling, hidden Markov modeling, and real time-PCR to comprehensively identify HrpL-responsive genes in P. syringae pv. tomato DC3000 and to develop a robust bioinformatic protocol for predicting Hrp promoters in all $P$. syringae genomes. We discuss below the methods we have developed and the implications of our findings in the context of other studies of virulence regulons and regulatory networks and the potential roles in pathogenesis of the genes in DC3000 that are regulated by HrpL.

\section{Methodology for identifying regulons.}

Although much previously was known about the HrpL regulon in DC3000, we wanted to ascertain the effectiveness of combining microarray expression data with clustering and bioinformatics techniques to identify putative regulons, without necessarily biasing such a search previously identified promoter sequences or coregulated genes. In this regard, our effort here has been rather successful; clustering analysis of the microarray expression data consistently reveals a well-correlated cluster that contains all of the known T3SS-related genes (as well as some others not so obviously related). Furthermore, Gibbs sampling of the entire set of upstream sequences implicated by the microarray consistently uncovers a promoter motif consistent with the Hrp promoter identified in previous work. The set of Hrp promoters discovered by the Gibbs sampling and subsequent HMM and PSWM scans is quite well correlated with the set of genes identified by clustering of expression profiles. The de novo reconstruction of the Hrp promoter motif did not use any prior knowledge of the motif (other than its approximate size expected on the basis of fact that HrpL is an ECF-type sigma factor). We expect a similar methodology to be applicable to the search for regulons of other sigma factors and transcription factors for which less is known experimentally. With discriminating HMM and PSWM models of Hrp promoter motifs in hand, we also can scan other sequenced genomes for candidate Hrp promoters. Application of this approach to $P$. syringae pv. phaseolicola $1448 \mathrm{~A}$ is described in a companion article (Vencato et al. 2006). In addition, this methodology has suggested both further experimentation to clarify the HrpL regulon and further refinements to the original genome annotation by focusing our attention on bioinformatically significant promoters that were not immediately upstream of differentially expressed target genes. In several cases, we have been able to use such information to annotate new hypothetical proteins whose functions can be the focus of future study.

\section{Comparisons with genome-enabled analyses of Hrp regulons in phytopathogenic bacteria.}

A study analogous to ours used a 70-mer oligonucleotidebased microarray to identify genes differentially regulated in Ralstonia solanacearum wild-type and $h r p B$ mutant strains (Occhialini et al. 2005). HrpB is an AraC-type positive activator of genes encoding the T3SS and its substrates and is important to the virulence of this bacterial wilt pathogen. The study by Occhialini and associates revealed that HrpB activates previously unknown candidate effectors as well as a variety of genes with functions unrelated to the T3SS. These included genes involved in chemotaxis and the metabolism of various low molecular weight compounds. The $R$. solanacearum Hrp regulon also included several transcriptional regulators as well 
as genes without an obvious HrpB-responsive promoter. Global study of the expression of $R$. solanacearum virulence genes also has been furthered by a genetic screen for HrpBactivated genes and by an in vivo expression technology analysis of genes that are differentially expressed in planta (Brown and Allen 2004; Mukaihara et al. 2004). These studies reveal overlapping sets of genes that are likely key to the virulence of $R$. solanacearum. In general, the $\mathrm{HrpB}$ regulon of $R$. solanacearum appears to be larger and more complex than the HrpL regulon of $P$. syringae.

Other experimental approaches also have provided evidence for HrpL-dependent regulation in DC3000, although in conditions involving $h r p L$ overexpression in rich medium rather than an $h r p L$ deletion in Hrp minimal medium (Chang et al. 2005; Fouts et al. 2002). We expect that some of the differences with previous work are due to these differences in the protocol. Regarding the two previous genetic screens, the reporter transposon screen of Fouts and associates (2002) was not intended to be saturating, whereas the more recent DFI screen of Chang and associates (2005) is more nearly so. The data from both genetic screens corroborate the bioinformatic analysis presented here: 35 operons with bioinformatically identified Hrp promoters were found to be HrpL dependent in both our hrpL deletion experiments and the earlier HrpL overexpression studies (Chang et al. 2005; Fouts et al. 2002). Ten operons not previously identified using HrpL overexpression were identified as differentially expressed in our $\Delta h r p L$-based assays. Eleven operons were differentially expressed under HrpL overexpression conditions but not in the $h r p L$ deletion conditions used here. Of those 11, 5 exhibited some differential expression in our microarray experiment (fold change $\geq 1.27$ ) but failed to meet all of our criteria for significant differential expression; another 3 of the 11 operons were not printed on our microarray and were not subsequently tested via real time-PCR. The significance during infection conditions of those operons that respond in culture to HrpL only when overexpressed is an important question for future research.

Table 2. Genes in putative operons that are preceded by HrpL-responsive promoters ${ }^{\mathrm{a}}$

\begin{tabular}{|c|c|c|c|c|c|}
\hline Locus ${ }^{b}$ & Protein & Locus & Protein & Locus & Protein \\
\hline 0044 & HopK1 & 1377 & AvrE1 & 3087 & AvrPtoB (HopAB2) \\
\hline 0061 & HopY1 & 1378 & Lytic transglycos. & 4001 & AvrPtol \\
\hline 0370 & MatE efflux domain & 1381 & HrpA1 & 4101 & HopAK 1 \\
\hline 0371 & IaaL & 1382 & HrpZ1 & 4331 & HopE1 \\
\hline 0473 & 'hopAS (pseudogene) & 1383 & HrpB & 4588 & HopS2 \\
\hline 0474 & HopAS1' & 1384 & HrcJ & 4589 & ShcS2 \\
\hline $5616^{\text {* }}$ & hypothetical & 1385 & HrpD & 4597 & HopS1' \\
\hline 0501 & HopU1 & 1386 & HrpE & 4599 & ShcS1 \\
\hline 0502 & HopF2 & 1387 & $\mathrm{HrpF}$ & 4691 & HopAD1 \\
\hline 0503 & ShcF & 1388 & HrpG & 4701 & HopAQ1 \\
\hline 0524 & M20/M25/M40 peptidase & 1389 & $\mathrm{HrcC}$ & 4718 & HopAA 1-2 \\
\hline 0588 & HopH1 & 1390 & HrpT & 4720 & HopV1 \\
\hline 0589 & HopCl & 1391 & $\mathrm{HrpV}$ & 4721 & ShcV \\
\hline 0834 & Alcohol DH & 1392 & $\mathrm{HrcU}$ & 4722 & HopAO1 \\
\hline 0835 & RibD C-terminal domain & 1393 & HrcT & 4727 & HopG1 \\
\hline 0836 & Phosphatase, putative & 1394 & $\mathrm{HrcS}$ & 4732 & HopQ1-2 \\
\hline 0837 & Conserved hypothetical & 1395 & HrcR & 4733 & hypothetical \\
\hline 0838 & Major facilitator transp. & 1396 & $\mathrm{HrcQb}$ & 4776 & HopI1 \\
\hline 0852 & HopAJ1 & 1397 & HrcQa & 5353 & ShcA \\
\hline $5617 *$ & unannotated & 1398 & HrpP & 5354 & HopA 1 \\
\hline 0876 & HopD1 & 1399 & $\mathrm{HrpO}$ & $\mathrm{A} 0005$ & HopAM1-2 \\
\hline 0877 & HopQ1-1 & 1400 & $\mathrm{HrcN}$ & $\mathrm{A} 0012$ & HopX1 \\
\hline 0883 & HopR1 & 1401 & HrpQ & $\mathrm{A} 0017$ & SchO1 \\
\hline $5619 *$ & unannotated & 1402 & $\mathrm{HrcV}$ & A0018 & HopO1-1 \\
\hline 0901 & HopAG1' & 1403 & HrpJ & A0019 & HopT1-1 \\
\hline 1022 & HopAM1-1 & 1405 & HrpK1 & B0005 & Phosphoesterase \\
\hline 1369 & ShcN & 1406 & HopB 1 & $\mathrm{~B} 0078^{*}$ & unannotated \\
\hline 1370 & HopN1 & 1568 & HopAF1 & & \\
\hline 1372 & HopAA 1-1 & $5620^{*}$ & unannotated & & \\
\hline 1373 & HrpW1 & 1645 & MarR/SlyA fam. & & \\
\hline 1374 & ShcM & 2105 & AbpE family & & \\
\hline 1375 & HopM1 & 2678 & HopP1 & & \\
\hline 1376 & ShcE & 2679 & Alcohol DH & & \\
\hline
\end{tabular}

${ }^{a}$ List of genes with bioinformatically-identified upstream Hrp promoters, for which there is experimental evidence for HrpL-dependent transcription or the gene is in a putative operon with other genes that are HrpL-dependent.

${ }^{\mathrm{b}}$ Genes are listed in order of their PSPTO locus number identifiers, with putative operons boxed with heavy black lines. Genes are presented in the order of their PSPTO number along the DC3000 chromosome, with plasmid-borne effector genes (PSPTO numbers preceded with letter A or B) being presented last. New gene calls included in our updated GenBank submission are noted with asterisks and placed in their appropriate operons. Designations for T3SS substrates follow current nomenclature recommendations (Lindeberg et al. 2005). Operons located on the plus strand are shaded green and those on the minus strand are shaded yellow. Abbreviations in protein designations: $\mathrm{DH}=$ dehydrogenase, facil. $=$ facilitator, fam. $=$ family, transglycos. $=$ transglycosylase, and transp. $=$ transporter. 


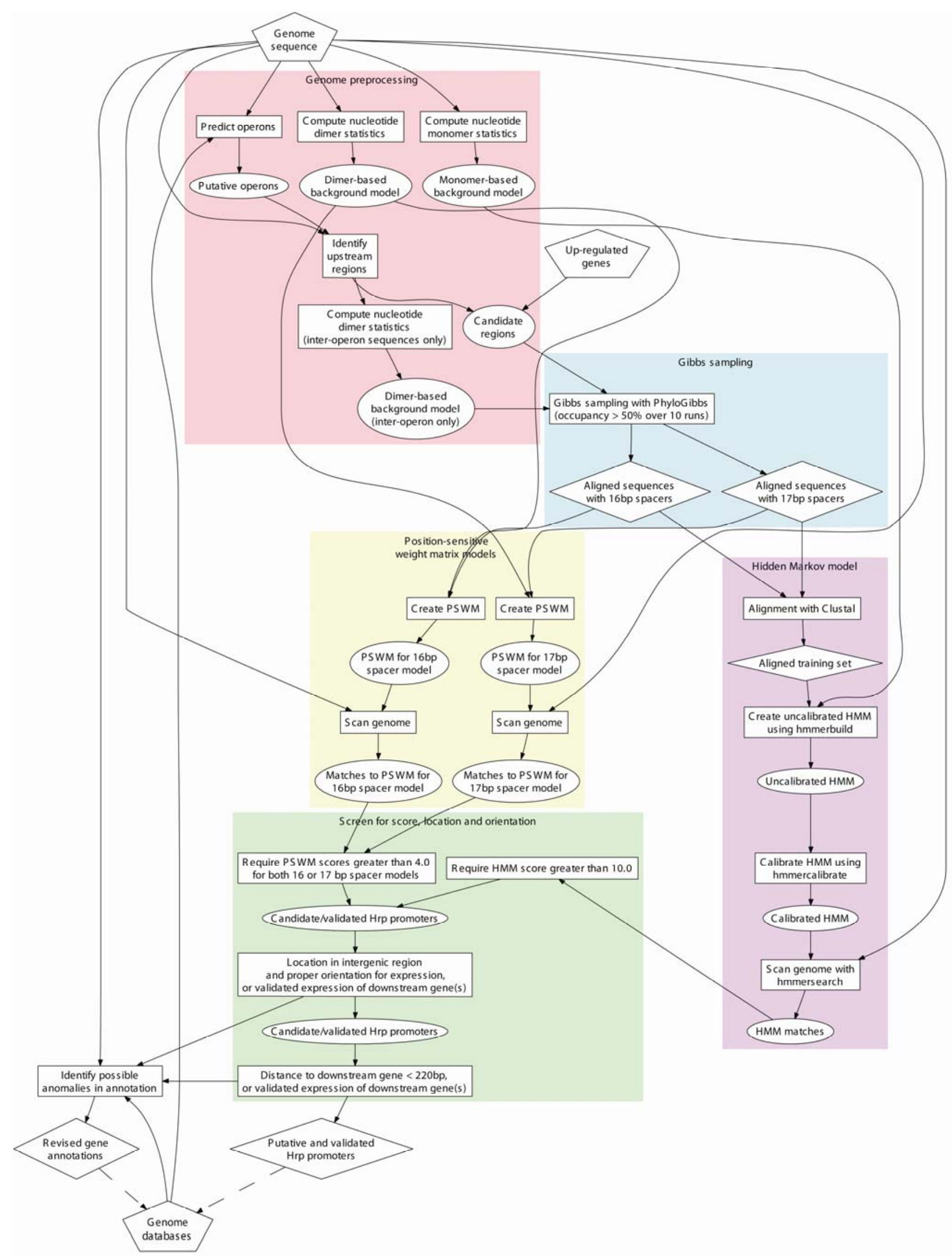

Fig. 5. Bioinformatic workflow represented as a directed graph. The major processing modules are grouped and highlighted by color. The nodes representing primary inputs, primary outputs, processing steps, and intermediate datasets are denoted with pentagons, diamonds, squares and ellipses, respectively. Feedback pathways that connect primary outputs to primary inputs are indicated by dashed arrows. 
Implications for regulatory networks and evolution.

Our search for regulatory binding motifs upstream of differentially expressed genes found no consistent motifs other than the Hrp promoter presumably bound by HrpL. The Hrp promoter signal is rather well conserved in DC3000, with a significant number of binding motifs in the genome, so perhaps our methods were able to detect that strong signal but missed weaker or fuzzier ones. On the other hand, the lack of other regulatory motifs upstream of the T3SS suggests that regulation of the T3SS is simply and directly controlled only by HrpL in Hrp minimal media. Comparisons between different $P$. syringae pathovars and other pseudomonads reveal that there is a great deal of genomic shuffling and transposition in the segments of the genome associated with the T3SS and its effectors (Feil et al. 2005; Joardar et al. 2005a,b). This shuffling appears to be associated with the needs of host specificity, which is largely what differentiates various pathovars. We hypothesize that adaptations to changes in host susceptibility targets and defense surveillance systems are countered by a dynamic process of effector gene horizontal acquisition and inactivation. This may make advantageous the simple and direct regulation of the T3SS through a single sigma factor rather than through the combinatorial control of multiple factors. In the absence of control by other factors, the timing of the synthesis and delivery of T3SS components may be governed by promoter affinity levels (e.g., as has been hypothesized for flagellar biosynthesis) (Kalir et al. 2001), a scenario that requires further investigation.

\section{Relationship between expression patterns and potential biological roles of HrpL-regulated genes.}

Most of the genes in the strongly up-regulated DEG-UP cluster 1 are associated with Hrp promoters with an HMM2 score $>10$, and most of these genes encode components of the T3SS and its substrates (Fig. 1; Table 2). The induction kinetics of the HrpL regulon observed here are consistent with that previously observed in $P$. syringae pv. phaseolicola using real time-PCR and genes encoding the T3SS and four substrate proteins (Thwaites et al. 2004). The genes in one subcluster are activated particularly rapidly. These encode the HrpA1 pilus protein, the HrpW1 and HrpZ1 harpins, the HrpK1 putative translocator, and the duplicated HopAM1 encoding genes (the " 1 " in each Hrp name follows the new nomenclature recommendations for T3SS substrates of Lindeberg and associates [2005]). Of these, HrpA1 and HrpK1 are involved in the initial deployment of the extracellular T3SS machinery. The rapid induction of the harpin and HopAM1 genes suggest that these are among the first proteins to travel the Hrp T3SS. Several of the HrpL-activated genes in DC3000 may be subject to more complex regulation and their relationship with the T3SS is not obvious. We will discuss several examples below.

Phytotoxin and phytohormone genes. The corR and $c f l$ genes control the biosynthesis of the phytotoxin coronatine (Bender et al. 1999). Coronatine is a methyl-jasmonate mimic whose activity antagonizes the plant salicylic acid-dependent defense pathway (He et al. 2004; Zhao et al. 2003). P. syringae pv. tomato DC3000 coronatine-deficient mutants are reduced in virulence in Arabidopsis (Brooks et al. 2004; Mittal and Davis 1995). The corR gene (PSPTO4704) is preceded by an Hrp promoter with an HMM2 score $>10$, and it appears to be in the same operon as hopAQ1 (PSPTO4703). The corR gene was not differentially expressed in our microarray analysis, which employed a $\Delta h r p L$ mutant, but it was identified as HrpL responsive in the DFI analysis, which used overexpression of $h r p L$. The coronatine biosynthesis $c f l$ genes are not linked with any discernable Hrp promoter but, nevertheless, are activated by HrpL, presumably through HrpL-activated CorR (Fouts et al. 2002). The significance of $\mathrm{HrpL}$ activation of the iaaL indoleacetetate lysine ligase gene (PSPTP0371) is unclear. As noted before, DC3000 carries genes necessary to produce the phytohormone indole acetic acid (IAA) and also iaaL, whose product would be expected to produce inactive IAA conjugates (Buell et al. 2003). The ability to produce IAA is widespread among $P$. syringae pathovars and other phytopathogenic bacteria; however, only DC3000 among the sequenced $P$. syringae pathovars carries iaaL. (Feil et al. 2005; Joardar et al. 2005a). Similar to corR, iaaL is expressed differentially in response to overexpression of $h r p L$ but not in wild-type DC3000 in experiments involving the $\Delta h r p L$ mutant for comparison.

Twin-arginine substrates. Both PSPTOB0005 and PSPTO3648 were recently identified as secreted by the twinarginine (TAT) pathway in DC3000 (Bronstein et al. 2005). Both were identified as being differentially expressed in the microarray, although we have since realized that both genes should not have been on the array because of their high sequence identity (approximately 90\% nucleotide similarity). Because PSPTOB0005 has an upstream Hrp promoter and PSPTO3648 does not, we assume that the strong differential expression observed for both was due to the expression of PSPTOB0005 and subsequent cross-hybridization. Nonetheless, because Bronstein and associates (2005) established a connection between the TAT and T3SS pathways, confirmation of HrpL-dependent expression for one of those substrates is intriguing.

Myo-inositol metabolism. The region PSPTO3500 to PSPTO3492 includes several operons that encode enzymes and transporters related to myo-inositol metabolism. None of these has a detectable Hrp promoter but all are tightly clustered in a subgroup of group 3 (Fig. 1). This subgroup is characterized by strong HrpL-dependent upregulation $3 \mathrm{~h}$ after the shift to inducing conditions followed by rapid downregulation. In contrast, genes nominally associated with other aspects of phytate and inositol phosphate metabolism (e.g., PSPTO1419, PSPTO3047, and PSPTO3241) are not differentially expressed. It is known that phosphoinositide-specific phospholipase $\mathrm{C}$ is transiently expressed by soybean cells during infection by $P$. syringae pv. glycinea with large concomitant changes in the concentrations of inositol polyphosphate species within host cells (Shigaki and Bhattacharyya 2000). This class of phospholipases also has been implicated in other biotic and abiotic stress responses in Arabidopsis (Ton et al. 2005). Therefore, it is possible that Hrp-dependent regulation of the inositolrelated catabolic genes in the region PSPTO3500 to PSPTO3492 may have a role in bacterial nutrition or defense suppression during infection.

Sigma factors and other transcription factors. The microarray experiment implicated several sigma factors and transcription factors in the set of differentially expressed genes. Specifically, the sigma factors PSPTO0537 (RpoD), PSPTO1565 (RpoS), and PSPTO2298 (SigW) all were upregulated, although none appear to be under direct control of $\mathrm{HrpL}$ (i.e., they do not have upstream Hrp promoters). However, PSPTO1645 (SlyA/MarR family) is both upregulated and preceded by an Hrp promoter. In addition, the negative regulator PSPTO1391 (HrpV) also was upregulated and would appear to be under direct control of HrpL as part of the $h r c C$ operon. Conversely, PSPTO1209 (a sigma-70 family protein) and PSPTO4224 (sigma-24) were found to be downregulated in the microarray, as were the transcriptional regulators PSPTO1379 ( $h r p R)$ and PSPTO1758 (in the TetR family). $h r p R$ is not preceded by an Hrp promoter or expected to be expressed in an HrpL-dependent manner. Rather, HrpR is a sigma-54 enhancer-binding protein that activates $h r p L$ expression (Xiao et al. 1994). Interestingly, real time-PCR analysis of $P$. syringae pv. phaseolicola 
revealed that $h r p R$ expression increased relatively weakly in Hrp minimal medium but much more strongly in planta (Thwaites et al. 2004). However, the focus of this work is on genes downstream of HrpL, rather than upstream, in the Hrp regulatory cascade. An obvious open question involves the regulation of all other genes differentially expressed in our microarray that do not have Hrp promoters. Although we have not found compelling evidence for other regulatory binding motifs, effort focused on the set of sigma factors and transcription factors which were themselves differentially expressed may provide insights into the regulation of those other genes.

\section{Conclusions.}

The expression of HrpL affects many genes in $P$. syringae pv. tomato DC3000, including several with no obvious role in the T3SS. Some of these, such as the coronatine biosynthesis genes, are known to have a role in pathogenesis; however, we think that all of these genes are high-priority candidates for future work by the $P$. syringae research community. As an example, we report in the accompanying article by Vencato and associates (2006) that PSPTO2105 (ApbE-family protein) and PSPTO0834 (alcohol dehydrogenase) mutants are partially reduced in their ability to grow in Arabidopsis leaves and that both of these genes have homologs in P. syringae pv. phaseolicola 1448A that also are preceded by Hrp promoters and activated by HrpL. In summary, we hope that this exhaustive bioinformatic and experimental analysis of the HrpL regulon of $P$. syringae pv. tomato DC3000 will provide a solid foundation for future functional analysis of this key virulence regulon in P. syringae.

\section{MATERIALS AND METHODS}

\section{Microarray design, fabrication, and use.}

$P$. syringae strains were grown in King's B (KB) (King et al. 1954) or hrp-derepressing fructose minimal medium (Hrp MM) (Huynh et al. 1989). DNA sequences corresponding to putative genes were identified using a draft version of the DC3000 genome. Primers were selected using Primer 3.0 (Rozen and Skaletsky 2000) to exhibit a melting temperature between 55 and $65^{\circ} \mathrm{C}$, a GC content of 50 to $65 \%$, and a length of 18 to 25 nucleotides. Amplicon lengths were constrained to range from 300 to $800 \mathrm{bp}$. Design was unsuccessful using these criteria for 527 genes and they were omitted from the array. These included two T3SS-related genes, hrpF (PSPTO1387) and hrpT (PSPTO1390). In cases where groups of genes were highly similar ( $>60$ bp with $>80 \%$ nucleotide identity), we chose one representative gene in each set in order to minimize cross-hybridization. All transposase genes were excluded due to their high abundance. The final array contained 5,033 unique amplified DNAs representing at least 4,843 of 5,673 predicted genes. Differences between the final version of the genome and the version used for primer design resulted in the inclusion of a small number of duplicated genes on the array as well as some sequences that are not annotated as genes.

The 5,033 sequences were PCR amplified from purified $P$. syringae pv. tomato DC3000 genomic DNA. PCR reactions were analyzed using 96-well Ready-To-Run precast agarose gels (Amersham Biosciences, Piscataway, NJ, U.S.A.), and $>99 \%$ were determined to have successfully yielded a single product. PCR products were purified using a Genesis RSP200 Liquid Handler (TECAN, Maennedorf, Switzerland) and 384well filter plates (S384PCR10; Millipore, Bedford, MA, U.S.A.), vacuum dried, and resuspended in $10 \mathrm{ml}$ of Pronto! spotting solution (Corning, Corning, NY, U.S.A.). Samples were spotted onto $\gamma$-amino-propyl-silane coated UltraGAPS slides (Corning) using a MicroGrid Pro arrayer (BioRobotics, Cambridge) with 32 MicroSpot 2500 printing pins. PCR products were fixed to the modified glass slides by treatment with $250 \mathrm{~mJ}$ of UV irradiation followed by a $2-\mathrm{h}$ incubation at $85^{\circ} \mathrm{C}$. An additional 806 PCR-control (blank) spots, containing primerless PCR reactions, were included on the array, as well as 137 spots containing only spotting solution (empty) for a total of 6,144 spots. Following fabrication, slides were stored in a dust-free plexiglass chamber (approximately $21^{\circ} \mathrm{C}, 0 \%$ relative humidity) in protective storage boxes (Corning). To test the microarray, a single-replicate pilot experiment was conducted comparing genomic DNA from wild-type DC3000 with that from a strain containing a deletion in the hrp/hrc pathogenicity island (Fouts et al. 2003). The results correctly identified $>95 \%$ of the genes deleted in the mutant strain (data not shown).

Two strains of DC3000, a wild-type strain and a strain containing a deletion in $h r p L$ (UNL-134-1), were used for gene expression profiling. DC3000 UNL-134-1 has a 2-kb deletion affecting $h r p L$. Bacterial cells grown overnight at $28^{\circ} \mathrm{C}$ in $\mathrm{KB}$ containing rifampicin at $50 \mu \mathrm{g} / \mathrm{ml}$ were harvested by centrifugation at 4,000 rpm for $5 \mathrm{~min}$ and resuspended in Hrp MM (Huynh et al. 1989) to an optical density at $600 \mathrm{~nm}\left(\mathrm{OD}_{600}\right)$ of approximately 0.5 . Cell cultures then were divided in $10-\mathrm{ml}$ aliquots and harvested at $0,2,3,4,5,6,7$, and $9 \mathrm{~h}$ after incubation at $18^{\circ} \mathrm{C}$. Cell pellets were resuspended in $200 \mu \mathrm{l}$ of RNAprotect (Qiagen, Valencia, CA, U.S.A.) prior to storing at $-20^{\circ} \mathrm{C}$. Three independent time course experiments were performed.

Total RNA was isolated using RNeasy midi kits (Qiagen) following the manufacturer's protocol. The optional on-column DNA digestion was performed. Isolated total RNA $(7 \mu \mathrm{g})$ was reverse transcribed in the presence of Cy3 or Cy5 dCTP using the ChipShot labeling system (Promega Corp., Madison, WI, U.S.A.) according to the manufacturer's protocol. cDNA of a given time point was labeled with either $\mathrm{Cy} 3$ or $\mathrm{Cy} 5$, such that each time point was differentially labeled in two of the three biological replicates. Labeled cDNAs were mixed following an incomplete block design (Chu et al. 2002; Churchill 2002; Kerr and Churchill 2001), and purified using QIAquick PCR purification spin columns (Qiagen). Purified labeled cDNAs were dried and resuspended in $70 \mu \mathrm{l}$ of Pronto! Universal Hydridization Solution (Corning). Meanwhile, microarray slides were prepared for hybridization according to the Pronto! systems protocol, but skipping the sodium borohydride wash step. Hybridization was carried out under lifter slips (Erie Scientific, Portsmouth, NH, U.S.A.) for 14 to $16 \mathrm{~h}$ at $42^{\circ} \mathrm{C}$. Slides were washed according to the Pronto! systems protocol, and then were dried immediately by centrifuging at $750 \mathrm{rpm}$ for $5 \mathrm{~min}$.

Microarray slides were scanned using a ScanArray5000 two-channel laser confocal microarray scanner (GSI Lumonics, Billerica, MA, U.S.A.) and the associated ScanArray software (v. 3.1; Packard BioChip Technologies, Boston, MA, U.S.A.) to obtain fluorescence images. Numerical representations of the fluorescence signals were obtained from the fluorescence images using the ImaGene software package (v. 5.6; Biodiscovery Inc., El Segundo, CA, U.S.A.). Numerical data were adjusted to account for hybridization inconsistencies across the surfaces of individual slides by implementing the spatial lowess algorithm (Cui et al. 2002) in the R environment for statistical computing. Data then were imported into the GeneSpring microarray data analysis environment (v. 6.1; Silicon Genetics, Redwood City, CA, U.S.A.), where the default intensitydependent normalization was applied. The data set was analyzed for genes showing an HrpL-dependent expression pattern. To be assigned to this group, a gene was required to have data for 
at least one time point with i) an average spot fluorescent intensity $>4,000$, ii) a Student's $t$ test $P$ value $<0.05$, and iii) a wild-type: $\Delta h r p L$ or a $\Delta h r p L$ :wild-type ratio $>1.4$.

\section{Real time-PCR.}

All RNA extractions were performed using RNase-free tubes, and filter tips and equipment were treated with RNAzap (Ambion, Austin, TX, U.S.A.). real time-PCR-grade water (Ambion) also was used for all procedures. A 2-ml overnight culture of each strain was grown in $\mathrm{KB}$ supplemented with rifampicin at $50 \mu \mathrm{g} / \mathrm{ml}$ and kanamycin at $50 \mu \mathrm{g} / \mathrm{ml}$. The cultures were reinoculated into $10 \mathrm{ml}$ of $\mathrm{KB}$ media supplemented with rifampicin at $50 \mu \mathrm{g} / \mathrm{ml}$ and kanamycin at $50 \mu \mathrm{g} / \mathrm{ml}$ to an $\mathrm{OD}_{600}$ of 0.1 and allowed to grow to an $\mathrm{OD}_{600}$ of 0.2 . Cells then were harvested from $1 \mathrm{ml}$ of culture by centrifugation at $13,000 \times g$ for $5 \mathrm{~min}$ and flash frozen in liquid nitrogen. Total RNA was prepared from cell pellets using the SV Total RNA Isolation System (Promega Corp.) according to the manufacturer's instructions. An additional DNase I digestion step was performed with DNA-free (Ambion) according to the rigorous DNase treatment included in the manufacturer's instructions. This additional DNase step was necessary to remove trace DNA contamination in the RNA preparation. RNA was purified further using the RNeasy Minikit (Qiagen) following the manufacturer's instructions. Quantification and sample integrity of RNA samples was assessed using spectrophotometer readings at an absorbance of $260 \mathrm{~nm}\left(A_{260}\right)$ and the $A_{260} / \mathrm{A} 280$ ratio, respectively.

Real-time PCR was performed by using the ABI 7000 Sequence Detection System (Applied Biosystems) and iTaq SYBR Green Supermix with Rox (Biorad) following the manufacturer's protocols. Total RNA (100 ng) extracted from strains of $P$. syringae pv. phaseolicola 1448a was reverse transcribed in a thermocycler using a cDNA synthesis kit (Biorad) according to the manufacturer's instructions. Then, $1 \mu \mathrm{l}$ of the resulting total $\mathrm{cDNA}$ population was mixed with $0.3 \mu \mathrm{M}$ concentrations of each primer and $12.5 \mu \mathrm{l}$ of master mix in a $25-\mu \mathrm{l}$ final volume. The PCR assay was carried out with one cycle at $95^{\circ} \mathrm{C}$ for $2.5 \mathrm{~min}$ followed by 35 cycles of $95^{\circ} \mathrm{C}$ for $15 \mathrm{~s}$ and $60^{\circ} \mathrm{C}$ for $30 \mathrm{~s}$. The amount of fluorescence that resulted from the incorporation of the SYBR Green dye into double-stranded DNA was measured at the end of each cycle to determine the kinetics of PCR for each sample. DNA contamination and the formation of primer dimers were assessed by using controls lacking reverse transcriptase and template, respectively. The production of nonspecific products was determined by the dissociation protocol included in the software provided with the ABI 7000 real-time PCR machine. The resulting threshold cycle $(\mathrm{Ct})$ values were calculated by the ABI 7000 software and analyzed using the relative standard curve method (separate tubes) described in ABI User Bulletin no. 2. In each strain, the $\mathrm{Ct}$ values of each gene tested were normalized to the $\mathrm{Ct}$ values of two housekeeping genes, gyrA and gapl, separately, and these values then were averaged to obtain relative expression data for each gene.

\section{Operon analysis and construction of candidate regulatory regions.}

Assignment to putative operons used a modification of the procedure described by Collado-Vides and associates (MorenoHagelsieb and Collado-Vides 2002; Salgado et al. 2000). The DC3000 genome was segmented into putative transcription units based on log likelihood ratios. In practice, all intraoperon intergenic separations are $\leq 60 \mathrm{bp}$. The set of candidate regulatory regions consisted of the regions from -265 to -15 bases relative to the transcription start site of the first gene in the putative transcription unit, unless the end of an upstream gene was reached before the -265 position was reached, in which case the candidate regulatory region was terminated there. Two manual curations to the operon data were made based on previous experimental evidence characterizing the HrpC operon (Deng et al. 1998) and the HrpK operon (Alfano et al. 2000; Petnicki-Ocwieja et al 2005). In addition, for two genes of interest for which separations between gene exceeded $50 \mathrm{bp}$ but were less than $60 \mathrm{bp}$, two putative operon starts were included: for gene PSPTO0713, sequence upstream of both PSPTO0713 and PSPTO0706 was included in the sampling set; and, for PSPTO0875, sequence upstream of both PSPTO0875 and PSPTO0874 was included. The first 15 bases upstream were stripped off to avoid including recurring ribosome binding sites in the sequence data, which can interfere with the detection of other regulatory motifs. Preliminary Gibbs sampling revealed nearly 150 identical bases upstream of PSPTO1022 (HopAM1-1) and PSPTOA0005 (HopAM1-2); because such sequence identity can unduly influence the identification of clusters within the Gibbs sampler, the sequence upstream of PSPTOA0005 was dropped from the sampling set. Accounting for putative operons sharing upstream sequence and the other modifications described above, the sampling set comprised 97 upstream sequence regions totaling 18,374 nucleotide bases.

\section{Clustering of differential expression profiles.}

The cDNA microarray expression clustering package developed by de Hoon and associates (de Hoon et al. 2004) was used through the Biopython interface provided (de Hoon et al. 2003). We performed clustering on the expression profiles of the 194 DEG-ALL genes using several different distance metrics. (In all cases, the default method for linkage clusteringpairwise maximum-linkage clustering-was used.) Clustering on the full set of 194 DEG-ALL genes was done using the uncentered correlation metric, applied to the logarithms of the expression fold changes. Clustering separately on the subset of 119 upregulated genes in DEG-UP and 76 downregulated genes in DEG-DOWN used the raw expression fold change data, with different correlation-based metrics (e.g., Pearson, Spearman rank, and Kendall's tau). In general, the correlationbased clustering methods performed better than distance-based methods. All of the correlation-based clustering methods gave roughly comparable results, especially with regard to the tight clustering of the known T3SS components. We have observed that there often is sizable variation of measured expression levels within a given operon; therefore, it would seem that distance-based metrics may not be especially useful for clustering without appropriate care.

\section{Gibbs sampling.}

We use Gibbs sampling techniques to do de novo motif identification in the set of candidate regulatory regions derived from the preliminary operon analysis; that is, to search for common regulatory motifs in the upstream regions of apparently coregulated genes as revealed by microarray expression data. Gibbs sampling was done using the Phylogibbs program by Siddharthan and associates (Siddharthan et al. 2005). Phylogibbs attempts to cluster common sequence motifs that are consistent with a weight matrix model of the motifs, and track the stability of those clusters through the repeated application of Monte Carlo moves which rearrange the organization of motifs and clusters. We have run Phylogibbs for a variety of upstream sequence sets, including DEG-ALL, DEG-UP, and DEG-DOWN. We report here results from sampling upstream of the genes in DEG-UP, having run 10 realizations of the Gibbs sampler, looking for promoter-sized motifs of a width 33 bases, and examining the resulting tracked clusters. For a 
given run, Phylogibbs reports occupancy statistics for each sequence motif (window) within a given cluster; these occupancies reflect the fraction of sampled configurations for which a sequence is attached to a cluster. We have averaged the occupancy fractions over the 10 runs, assigning an occupancy of 0 if a sequence does not appear in a given cluster in a given run. From the Gibbs sampler and the resulting occupancy statistics, we have identified a set of strongly co-clustered sequences for use in further analysis.

\section{HMMs.}

The HMMer 2.3.2 package (Eddy 1998) was used for all HMM searches. The null model for the entire $P$. syringae pv. tomato DC3000 genome was created by computing the single nucleotide frequencies from both strands of the complete genomic sequences for the main chromosome (NCBI RefSeq accession NC_004578) and both native plasmids, pDC3000A (NCBI RefSeq accession NC_004633) and pDC3000B (NCBI RefSeq accession NC_004632) using the program compseq from the EMBOSS suite (Rice et al. 2000). When necessary, the submodels identified by Gibbs sampling differing primarily in the separations between the nominal " -35 " and " -10 " regions were combined by aligning the sequences using ClustalX (Thompson et al. 1997). The HMMs were constructed from the aligned sequences and the null model using the default parameter settings using hmmbuild, then calibrated with hmmcalibrate by sampling $5 \times 10^{4}$ randomly generated sequences with a mean length of 500 bases and standard deviation of 100 bases. The resulting calibrated HMM was used to search both strands of the three genomic sequences listed above using hmmsearch with a score of 10.0 (an $E$ value cutoff of $1 \times 10^{-3}$ ). This cutoff value was determined empirically by examining the matches generated by all of the models and attempting to retain as many matches as possible in intergenic regions with orientations consistent with promoter activity while minimizing the total number of matches occurring in annotated coding regions, in intergenic regions but with orientation inconsistent with promoter activity, and in intergenic regions between convergently transcribed genes.

\section{WM models.}

As a secondary, alternative bioinformatic model, the set of co-clustered sequences identified for the Gibbs sampler also has been analyzed with PSWMs, which typically do not allow for gaps; therefore, promoter sequences with different separations between the -35 and -10 boxes must be separated into distinct groups. For the Hrp-promoter-related motifs identified by the Gibbs sampler, we have generated two WMs for separations of length 16 and $17 \mathrm{bp}$, respectively. The resulting WMs then were used to scan the entire DC3000 genome to look for high-scoring motifs. PSWM-based methods provide no intrinsic cutoff threshold; therefore, a background model was constructed to assess statistical significance. Noncoding regions in DC3000 were assembled and analyzed for the frequency of monomer $(\mathrm{N}=1)$ and dimer $(\mathrm{N}=2)$ motifs, and 100,000 random sequences, drawn from a distribution consistent with the $\mathrm{N}=1$ and $\mathrm{N}=2$ statistics, were generated. Raw PSWM scores were converted to scaled scores reflecting the number of standard deviations above the mean of the background score distribution. Motifs with scores above 4.0 for both the 16- and 17bp spacer models were included as candidates.

\section{ACKNOWLEDGMENTS}

This work was supported by the NSF Plant Genome Research Program Cooperative Agreement DBI-0077622. C. R. Myers and G. B. Martin acknowledge support from the United States Department of Agriculture-
Agricultural Research Service under Specific Cooperative Agreements 5819074428 and 5819071139, respectively. C. R. Myers wishes to thank R. Siddharthan and E. Siggia for use of, and consultation regarding, their Phylogibbs program.

\section{LITERATURE CITED}

Alfano, J. R., Charkowski, A. O., Deng, W.-L., Badel, J. L., PetnickiOcwieja, T., van Dijk, K., and Collmer, A. 2000. The Pseudomonas syringae Hrp pathogenicity island has a tripartite mosaic structure composed of a cluster of type III secretion genes bounded by exchangeable effector and conserved effector loci that contribute to parasitic fitness and pathogenicity in plants. Proc. Natl. Acad. Sci. U.S.A. 97:4856-4861.

Arnold, D., Pittman, A., and Jackson, R. 2003. Pathogenicity and other genomic islands in plant pathogenic bacteria. Mol. Plant Pathol. 4:407420.

Bender, C. L., Alarcon-Chaidez, F., and Gross, D. C. 1999. Pseudomonas syringae phytotoxins: Mode of action, regulation, and biosynthesis by peptide and polyketide synthetases. Microbiol. Mol. Biol. Rev. 63:266292.

Bronstein, P. A., Marrichi, M., Cartinhour, S., Schneider, D. J., and Delisa, M. P. 2005. Identification of a twin-arginine translocation system in Pseudomonas syringae pv. tomato DC3000 and its contribution to pathogenicity and fitness. J. Bacteriol. 187:8450-8461.

Brooks, D., Hernandez-Guzman, G., Koek, A. P., Alarcon-Chaidez, F., Sreedharan, A., Rangaswarmy, V., Penaloza-Vasquez, A., Bender, C. L., and Kunkel, B. N. 2004. Identification and characterization of a welldefined series of coronatine biosynthetic mutants of Pseudomonas syringae pv. tomato DC3000. Mol. Plant-Microbe Interact. 17:162-174.

Brown, D. G., and Allen, C. 2004. Ralstonia solanacearum genes induced during growth in tomato: An inside view of bacterial wilt. Mol. Microbiol. 53:1641-1660.

Buell, C. R., Joardar, V., Lindeberg, M., Selengut, J., Paulsen, I. T., Gwinn, M. L., Dodson, R. J., Deboy, R. T., Durkin, A. S., Kolonay, J. F., Madupu, R., Daugherty, S., Brinkac, L., Beanan, M. J., Haft, D. H., Nelson, W. C., Davidsen, T., Liu, J., Yuan, Q., Khouri, H., Fedorova, N., Tran, B., Russell, D., Berry, K., Utterback, T., Vanaken, S. E., Feldblyum, T. V., D’Ascenzo, M., Deng, W.-L., Ramos, A. R., Alfano, J. R., Cartinhour, S., Chatterjee, A. K., Delaney, T. P., Lazarowitz, S. G., Martin, G. B., Schneider, D. J., Tang, X., Bender, C. L., White, O., Fraser, C. M., and Collmer, A. 2003. The complete sequence of the Arabidopsis and tomato pathogen Pseudomonas syringae pv. tomato DC3000. Proc. Natl. Acad. Sci. U.S.A. 100:10181-10186.

Chang, J. H., Urbach, J. M., Law, T. F., Arnold, L. W., Hu, A., Gombar, S., Grant, S. R., Ausubel, F. M., and Dangl, J. L. 2005. A high-throughput, near-saturating screen for type III effector genes from Pseudomonas syringae. Proc. Natl. Acad. Sci. U.S.A. 102:2549-2554.

Chu, T. M., Weir, B., and Wolfinger, R. 2002. A systematic statistical linear modeling approach to oligonucleotide array experiments. Math Biosci. 176:35-51

Churchill, G. A. 2002. Fundamentals of experimental design for cDNA microarrays. Nat. Genet. 32(Suppl.):490-495.

Crooks, G. E., Hon, G., Chandonia, J. M., and Brenner, S. E. 2004. WebLogo: A sequence logo generator. Genome Res. 14:1188-1190.

Cui, X., Kerr, K., and Churchill, G. 2002. Transformations for cDNA microarray data. Stat. Apps. Gen. Mol. Biol. 2:1-20.

de Hoon, M. J., Imoto, S., Nolan, J., and Miyano, S. 2004. Open source clustering software. Bioinformatics 20:1453-1454.

de Hoon, M. J. L., Chapman, B., and Friedberg, I. 2003. Bioinformatics and computational biology with Biopython. Genome Inf. 14:298-299.

Deng, W.-L., Preston, G., Collmer, A., Chang, C.-J., and Huang, H.-C. 1998. Characterization of the $h r p C$ and hrpRS operons of Pseudomonas syringae pathovars syringae, tomato, and glycinea and analysis of the ability of $h r p F, h r p G, h r c C, h r p T$, and $h r p V$ mutants to elicit the hypersensitive response and disease in plants. J. Bacteriol. 180:4523-4531.

Eddy, S. R. 1998. Profile hidden Markov models. Bioinformatics 14:755763.

Feil, H., Feil, W. S., Chain, P., Larimer, F., Dibartolo, G., Copeland, A., Lykidis, A., Trong, S., Nolan, M., Goltsman, E., Thiel, J., Malfatti, S., Loper, J. E., Lapidus, A., Detter, J. C., Land, M., Richardson, P. M., Kyrpides, N. C., Ivanova, N., and Lindow, S. E. 2005. Comparison of the complete genome sequences of Pseudomonas syringae pv. syringae B728a and pv. tomato DC3000. Proc. Natl. Acad. Sci. U.S.A. 102:11064-11069.

Fouts, D. E., Abramovitch, R. B., Alfano, J. R., Baldo, A. M., Buell, C. R., Cartinhour, S., Chatterjee, A. K., D’Ascenzo, M., Gwinn, M. L., Lazarowitz, S. G., Lin, N.-C., Martin, G. B., Rehm, A. H., Schneider, D. J., van Dijk, K., Tang, X., and Collmer, A. 2002. Genomewide identification of Pseudomonas syringae pv. tomato DC3000 promoters con- 
trolled by the HrpL alternative sigma factor. Proc. Natl. Acad. Sci. U.S.A. 99:2275-2280

Fouts, D. E., Badel, J. L., Ramos, A. R., Rapp, R. A., and Collmer, A. 2003. A Pseudomonas syringae pv. tomato DC3000 Hrp (type III secretion) deletion mutant expressing the Hrp system of bean pathogen $P$. syringae pv. syringae 61 retains normal host specificity for tomato. Mol. Plant-Microbe Interact. 16:43-52

Guo, M., Chancey, S. T., Tian, F., Ge, Z., Jamir, Y., and Alfano, J. R. 2005. Pseudomonas syringae type III chaperones $\mathrm{ShcO} 1, \mathrm{ShcS1}$, and ShcS2 facilitate translocation of their cognate effectors and can substitute for each other in the secretion of HopO1-1. J. Bacteriol. 187:4257-4269.

He, P., Chintamanani, S., Chen, Z., Zhu, L., Kunkel, B. N., Alfano, J. R., Tang, X., and Zhou, J.-M. 2004. Activation of a COI1-dependent pathway in Arabidopsis by Pseudomonas syringae type III effectors and coronatine. Plant J. 37:589-602.

Hirano, S. S., and Upper, C. D. 2000. Bacteria in the leaf ecosystem with emphasis on Pseudomonas syringae-a pathogen, ice nucleus, and epiphyte. Microbiol. Mol. Biol. Rev. 64:624-653.

Huynh, T. V., Dahlbeck, D., and Staskawicz, B. J. 1989. Bacterial blight of soybean: Regulation of a pathogen gene determining host cultivar specificity. Science 245:1374-1377.

Innes, R. W., Bent, A. F., Kunkel, B. N., Bisgrove, S. R., and Staskawicz, B. J. 1993. Molecular analysis of avirulence gene avrRpt2 and identification of a putative regulatory sequence common to all known Pseudomonas syringae avirulence genes. J. Bacteriol. 175:4859-4869.

Joardar, V., Lindeberg, M., Jackson, R. W., Selengut, J., Dodson, R., Brinkac, L. M., Daugherty, S. C., DeBoy, R., Durkin, A. S., Giglio, M. G., Madupu, R., Nelson, W. C., Rosovitz, M. J., Sullivan, S., Haft, D. H., Creasy, T., Davidsen, T., Zafar, N., Zhou, L., Halpin, R., Holley, T., Khouri, H., Feldblyum, T., White, O., Fraser, C. M., Chatterjee, Cartinhour, S., Schneider, D. J., Mansfield, J., Collmer, A., and Buell, C. R. 2005a. Whole genome sequence analysis of Pseudomonas syringae pv. phaseolicola 1448A reveals sequence divergence among pathovars in genes involved in virulence and mobile genetic elements. J. Bacteriol. 187:6488-6498.

Joardar, V., Lindeberg, M., Schneider, D. J., Collmer, A., and Buell, C. R. 2005b. Lineage specific regions in Pseudomonas syringae pv. tomato DC3000. Mol. Plant Pathol. 6:53-64.

Kalir, S., McClure, J., Pabbaraju, K., Southward, C., Ronen, M., Leibler, S., Surette, M. G., and Alon, U. 2001. Ordering genes in a flagella pathway by analysis of expression kinetics from living bacteria. Science 292:2080-2083

Kerr, M. K., and Churchill, G. A. 2001. Experimental design for gene expression microarrays. Biostatistics 2:183-201.

King, E. O., Ward, M. K., and Raney, D. E. 1954. Two simple media for the demonstration of pyocyanin and fluorescin. J. Lab. Clin. Med. 44:301-307.

Lindeberg, M., Stavrinides, J., Chang, J. H., Alfano, J. R., Collmer, A., Dangl, J. L., Greenberg, J. T., Mansfield, J. W., and Guttman, D. S. 2005. Proposed guidelines for a unified nomenclature and phylogenetic analysis of type III Hop effector proteins in the plant pathogen Pseudomonas syringae. Mol. Plant-Microbe Interact. 18:275-282.

Mittal, S., and Davis, K. R. 1995. Role of the phytotoxin coronatine in the infection of Arabidopsis thaliana by Pseudomonas syringae pv. tomato. Mol. Plant-Microbe Interact. 8:165-171.

Moreno-Hagelsieb, G., and Collado-Vides, J. 2002. A powerful non-homology method for the prediction of operons in prokaryotes. Bioinformatics 18(Suppl. 1):S329-36.

Mukaihara, T., Tamura, N., Murata, Y., and Iwabuchi, M. 2004. Genetic screening of Hrp type III-related pathogenicity genes controlled by the HrpB transcriptional activator in Ralstonia solanacearum. Mol. Microbiol. 54:863-75.

Occhialini, A., Cunnac, S., Reymond, N., Genin, S., and Boucher, C. 2005. Genome-wide analysis of gene expression in Ralstonia solanacearum reveals that the hrpB gene acts as a regulatory switch controlling multiple virulence pathways. Mol. Plant-Microbe Interact. 18:938-949.

Peñaloza-Vázquez, A., Preston, G. M., Collmer, A., and Bender, C. L. 2000. Regulatory interactions between the Hrp type III protein secretion system and coronatine biosynthesis in Pseudomonas syringae pv. tomato DC3000. Microbiology 146:2447-2456.

Petnicki-Ocwieja, T., van Dijk, K., and Alfano, J. R. 2005. The hrpK operon of Pseudomonas syringae pv. tomato DC3000 encodes two pro- teins secreted by the type III (Hrp) protein secretion system: HopB1 and $\mathrm{HrpK}$, a putative type III translocator. J. Bacteriol. 187:649-663.

Preiter, K., Brooks, D. M., Penaloza-Vazquez, A., Sreedharan, A., Bender, C. L., and Kunkel, B. N. 2005. Novel virulence gene of Pseudomonas syringae pv. tomato strain DC3000. J. Bacteriol. 187:7805-7814.

Rice, P., Longden, I., and Bleasby, A. 2000. EMBOSS: The European Molecular Biology Open Software Suite. Trends Genet. 16:276-277.

Rohmer, L., Guttman, D. S., and Dangl, J. L. 2004. Diverse evolutionary mechanisms shape the type III effector virulence factor repertoire in the plant pathogen Pseudomonas syringae. Genetics 167:1341-1360.

Rozen, S., and Skaletsky, H. 2000. Primer3 on the WWW for general users and for biologist programmers. Methods Mol. Biol. 132:365-386.

Salgado, H., Moreno-Hagelsieb, G., Smith, T. F., and Collado-Vides, J. 2000. Operons in Escherichia coli: Genomic analyses and predictions. Proc. Natl. Acad. Sci. U.S.A. 97:6652-6657.

Shen, H., and Keen, N. T. 1993. Characterization of the promoter of avirulence gene D from Pseudomonas syringae pv. tomato. J. Bacteriol. 175:5916-5924.

Shigaki, T., and Bhattacharyya, M. K. 2000. Decreased inositol 1,4,5trisphosphate content in pathogen-challenged soybean cells. Mol. PlantMicrobe Interact. 13:563-567.

Siddharthan, R., Siggia, E. D., and van Nimwegen, E. 2005. PhyloGibbs: A Gibbs sampling motif finder that incorporates phylogeny. PLoS Comput. Biol. 1:534-556.

Thompson, J. D., Gibson, T. J., Plewniak, F., Jeanmougin, F., and Higgins, D. G. 1997. The CLUSTAL_X windows interface: Flexible strategies for multiple sequence alignment aided by quality analysis tools. $\mathrm{Nu}-$ cleic Acids Res. 25:4876-4882

Thwaites, R., Spanu, P. D., Panopoulos, N. J., Stevens, C., and Mansfield, J. W. 2004. Transcriptional regulation of components of the type III secretion system and effectors in Pseudomonas syringae pv. phaseolicola. Mol. Plant-Microbe Interact. 17:1250-1258.

Ton, W. J., Jakab, G., Toquin, V., Flors, V., Iavicoli, A., Maeder, M. N., Metraux, J.-P., and Mauch Mania, B. 2005. Dissecting the beta-aminobutyric acid induced priming phenomenon in Arabidopsis. Plant Cell 17:987-999.

Vencato, M., Tian, T., Alfano, J. R., Buell, C. R., Cartinhour, S., DeClerck, J., Guttman, D. S., Joardar, V., Lindeberg, M., Mansfield, J., Myers, C. R., Collmer, A., and Schneider, D. J. 2006. The Hrp (type III secretion system) regulon and effector genes of Pseudomonas syringae pv. phaseolicola 1448A. Mol. Plant-Microbe Interact. 19:1193-1206.

Xiao, Y., Heu, S., Yi, J., Lu, Y., and Hutcheson, S. W. 1994. Identification of a putative alternate sigma factor and characterization of a multicomponent regulatory cascade controlling the expression of Pseudomonas syringae pv. syringae Pss61 hrp and hrmA genes. J. Bacteriol. 176:1025-1036.

Xiao, Y., and Hutcheson, S. 1994. A single promoter sequence recognized by a newly identified alternate sigma factor directs expression of pathogenicity and host range determinants in Pseudomonas syringae. J. Bacteriol. 176:3089-3091.

Zhao, Y., Thilmony, R., Bender, C. L., Schaller, A., He, S. Y., and Howe, G. A. 2003. Virulence systems of Pseudomonas syringae pv. tomato promote bacterial speck disease in tomato by targeting the jasmonate signaling pathway. Plant J. 36:485-499.

Zwiesler-Vollick, J., Plovanich-Jones, A. E., Nomura, K., Brandyopadhyay, S., Joardar, V., Kunkel, B. N., and He, S. Y. 2002. Identification of novel hrp-regulated genes through functional genomic analysis of the Pseudomonas syringae pv. tomato DC3000 genome. Mol. Microbiol. 45:12071218.

\section{AUTHOR-RECOMMENDED INTERNET RESOURCES}

BioPythonwebsite: www.biopython.org

EMBOSS, The European Molecular Biology Open Software Suite: emboss.sourceforge.net

Institute of Genetics and Molecular and Cellular Biology ClustalX windows interface: www-igbmc.u-strasbg.fr/BioInfo/ClustalX Profile hidden Markov model software: hmmer.wustl.edu (Eddy 1998) Pseudomonas-Plant Interaction website: pseudomonas-syringae.org The R Project for statistical computing: www.r-project.org WebLogo website: weblogo.berkeley.edu 